MATEC Web of Conferences 22,01036 (2015)

DOI: $10.1051 /$ matec conf/ 20152201036

(C) Owned by the authors, published by EDP Sciences, 2015

\title{
Game System for Rehabilitation Based on Kinect is Effective for Mental Retardation
}

\author{
Ying Fu, Jinfeng Wu, Shasha Wu, Hao Chai \& Yun Xu \\ Department of Psychology, Zhejiang University of Technology, Hangzhou, Zhejiang, China
}

\begin{abstract}
Kinect has already been widely used in the area of retardation, and this study is to evaluate whether the Game System for Rehabilitation based on Kinect is effective for children with mental retardation. The subjects in this paper are 112 children with mental retardation in Zhejiang province of China. The Game System for Rehabilitation based on Kinect was applied to assist the rehabilitation of children. Before the training, the Pediatric Evaluation of Disability Inventory (PEDI) was used to evaluate abilities of children, including self-care, mobility, and social function. And after having been trained for a month, the abilities of these children were evaluated again by PEDI. The results in this paper is that, after the application of Game System for Rehabilitation based on Kinect, the PEDI score of children is significantly higher than the score before training. And it can be concluded that the Game System for Rehabilitation based on Kinect can significantly improve self-care, mobility, and social function of children with MR.
\end{abstract}

Keywords: mental retardation; Game System; rehabilitation; PEDI; virtual reality; Kinect

\section{INTRODUCTION}

\subsection{Background}

Mental retardation (MR) is defined as significantly sub-average intellectual functioning accompanied by deficits or impairments in adaptive functioning that are evident before 18 (DSM IV).

The mental retardation is presented in about 2 to 3 percent of the population (Daily et al.2000). A review of the epidemiology of MR in children indicated that the actual measured prevalence varies considerably with ranges as high as $9.7 \%$ in children aging from 10 to 14 (Murphy et al. 1998). Creating an efficient, convenient, interesting rehabilitation training system for these special children is a research topic which will never fade.

\subsection{Rehabilitation for children with MR}

1.2.1 Deficiency of traditional rehabilitation therapy Special education and particular therapies are necessary on account of the difficulties for children with MR to learn to walk, talk and even develop social skills (Daily et al., 2000), However, the existing special education and therapies still have some deficiencies.

Shea (2006) pointed out that mainstream special schools are naturally built around a traditional academic model and have finite resources, which make it a challenge for them to provide a sufficiently varied and interesting program for children with MR. Some children spend time on tracing letters or doing repetitive worksheets year after year in well-intentioned attempts to include them in "academic" activities (Shea, 2006). And it leads to a more severe degree of learning difficulty (Shea, 2006). What's more, boredom may cause retreat behaviors, such as disruptive behavior (Felicinano et al. 2009). And the opportunities that special schools provide to build functional skills and leisure skills are inadequate (Shea, 2006), while taking part in leisure activities is a way to develop social skills and physical fitness (Tudor \& Tudor, 2013). It's necessary for children with MR to take part in a series of leisure activities, games, or exercise, for children with MR are at increasing risk of obesity or poor fitness (Burkhart et al 1985).

Another thorny problem we are facing is rehabilitation costs. The cost is too high to afford for some families. A general investigation in Nanjing, China is reported that $40 \%$ of families can barely afford the economic burden which their children with mental retardation and nearly $20 \%$ of families are already unable to bear; children in half of families with seriously mental retardation could not afford the cost which medical expenses accounted for a considerable proportion (Zhang, 2006). All treatments for habit disorders exhibited by individuals with mental retardation are therapist-mediated treatments as they are opposed to self-management treatments (Long, 1998), the costs are predictable. Meanwhile, a therapist's innate musicality, social sensitivity, clinical training, and experience are also important (Luck, 2010), it's also undoubtedly related to the cost of treatment.

What's more, children with MR are always limited in scope a result from MR is generally together with dyskinesia (Gualtieri et al. 1986), and the mobility should be taken into consideration when under therapy.

This is an Open Access article distributed under the terms of the Creative Commons Attribution License 4.0, which permits unrestricted use, distribution, and reproduction in any medium, provided the original work is properly cited. 


\subsubsection{Form of games can support rehabilitation}

In recent years, attracting and holding the child's attention which is to be involved in interaction is the role which must be adhered to the programmer in preparing the command which is to be used in rehabilitation (Miskam et al 2014). The therapy form of games has been widely used in children with MR, it has become an important treatment method (Fernando et al. 2012). The game played an extremely important role in child's physical and psychological development, and the form of game is adopted to their cognition style (Petrovska, 2013), and playing games that also provides some opportunities for the children to communicate (Miskam et al. 2014). The game satisfies the biological and psychological needs of children and contributes to their mental, emotional, social and moral development (Petrovska, 2013). Playing different roles in the games, although it's the product of a child's fantasy, it allows the child to gain good or bad personal experiences, which are about what is positive or not in behavior (Petrovska, 2013). In addition, the game as a safe and effective form of therapy also has the necessity of its existence (Axline, 1989). Children with MR are often accompanied by dyskinesia (Gualtieri et al. 1986), these children cannot take part in games and activities that are involved in strenuous exercise (Scardovell \& Frere, 2014). The use of games and even the games based on virtual reality (VR) could be an interesting adjuvant to conventional treatment for these children (Bonnechere et al. 2014). The lack of motivation is an important factor that clinicians need to deal with (Bonnechere et al. 2014; Alankus et al. 2011). However, it is precise that the forms of game make treatment itself interesting, attractive, and every child likes to play games. It makes therapy attract and hold the child's attention to involve in interaction (Miskam et al. 2014). The form of games has been proved to be effective in many ways, such as limb rehabilitation (Bandeira et al. 2014), functional balance and mobility (Marie \& Heidi, 2011), alteration of perceptual and cognitive abilities in addition to motor and sensory deficits (Ritterband-Rosenbaum et al. 2012).

\subsubsection{Kinect, a supportive sensor for rehabilitation}

Kinect is a motion sensing input device for the Xbox 360 video game console (Parry et al. 2014), which can capture users' actions through 3D technology and interpret those movements as well as support the voice-recognition technology, understanding users' words (Zhang, 2012).

With the emergence of Kinect for Windows, because of Kinect's diversified functions and low price (Zhang, 2012), many researchers, are leveraging Kinect to develop and transform this new innovational human-computer interaction in multiple industries, computer science (Liebling \& Morris 2012), E-Commerce (Pereira et al. 2011), robotics (Ellaithy et al. 2012), education (Hsu, 2011), and so on, and to perform other tasks.
Nowadays, the use of the commercial video games as rehabilitation tools has gained much interest in the physical therapy arena (Lange et al. 2011). Kinect as a new type of console has lots of advantages in rehabilitation training for children with mental retardation, which are proved to be more effective than those traditional methods (Yeung et al. 2014).

The first advantage of Game System for Rehabilitation based on Kinect is the low cost, which allows more people to get the rehabilitation medical training (Lange et al. 2011). As Laura (2013) pointed out, the low cost video games based on motion capture are potential tools in the rehabilitation context in exceptional child, whose research had showed improvements in balance and ADL in CP participants in a school environment (Luna-Oliva et al. 2013).

As it is mentioned earlier, there are difficulties for children with MR to learn to walk, talk and even develop social skills (Pereira et al. 2011), so the independence in activities of daily life (ADL) is an ultimate goal of rehabilitation for children with MR, which is a challenge in hospitals and clinics because of the lack of natural settings (Chung et al. 2014). While Kinect games integrated with virtual reality (VR) which simulates a home environment can provide a natural environment (Chung et al. 2014), to break the limitation of traditional rehabilitation training, it makes the rehabilitation training become more personal and easier to be spread.

Besides, Hui-mei's (2011) research pointed out that the affordances that Kinect provided can make interactions types enjoyable, interesting, and boost child's motivation that has been proved to be a problem which needs to deal with (Bonnechere et al. 2014; Alankus et al. 2011) and promote the ability of learning via its multimedia and multi-sensory (Hsu, 2011).

Also, in such a good environment, rehabilitation based on Kinect makes it possible to avoid the withdrawal behaviors (Niklasson et al. 2009). For example, it provides freedom of eye contact which can disturb children with MR during the treatment (Roebel \& MacLean, 2007).

In other words, the development of mentally disabled children in intelligence and body movement is imperfect. Bartoli's (2013) findings of the study provide some empirical evidence that motion-based touchless games can promote attention skills for exceptional children with low-moderate cognitive deficit, low-medium sensory-motor dysfunction, and motor autonomy (Bartoli et al. 2013).

In summary, applying Kinect to the game for rehabilitation can make the training be easy to operate (Jiang \& Jie, 2013) and be safe (Pompeu et al. 2014). It can also achieve the purpose of virtual reality (Bao et al. 2013), and emotional involvement (Di Tore et al. 2012). And it can help children to develop social skills (Duarte et al. 2013) which they are short of. 


\section{MATERIALS \& METHODS}

\subsection{Participant}

All 112 children with mental retardation from Hangzhou, Xiaoshan, Xiangshan, Huzhou, Wenling, Shaoxing, Tiantai, Zhejiang province of China, whose age varing from 3 to 18 years old, took part in our study. According to their medical records, there are 27 children who are mildly mental-retarded, 67 children who are moderately mental-retarded, and 18 children who are severely mental-retarded.

\subsection{Material}

2.2.1 Game system for rehabilitation based on Kinect With colorful images, vivid voice prompt and game sound, the Game System for Rehabilitation based on Kinect, was designed for children with special needs who are more than 3 years old, and it consists of five modules, each module includes 4 to 6 games with three difficulty levels that users can choose the game and difficulty level freely.

The Game System for Rehabilitation based on Kinect was developed for the purpose of satisfying the different rehabilitation demands of the autism, cerebral palsy, mental retardation, and other special groups. It consists of the mental rehabilitation program, the basic perceptual and cognitive program, the upper limb rehabilitation program, the lower limb rehabilitation program, and the leisure-healthcare program.

The mental rehabilitation program is mainly used for rehabilitation of intelligence, involving in different cognitive processes such as memory and classification Basic perceptual and cognitive training program is mainly used for rehabilitation of perception and cognition, involving the learning of Shape perception, reasoning, and digital, text, and so on. The upper limb rehabilitation program mainly aims at the rehabilitation of gross motor and fine motor of the arm, shoulder and fingers. The lower limb rehabilitation program is related to the rehabilitation of the lower limb muscle strength, balance and coordination, and control ability. The leisure-healthcare program is a kind of comprehensive rehabilitation training, mainly provides recreational activities as well as the rehabilitation in different aspects such as the cognitive and motion for the special groups.

Each module has an emphasis, and each program of rehabilitation is not completely independent but interacting with each other, which can be based on to provide comprehensive rehabilitation training for special groups.

\subsubsection{Pediatric Evaluation of Disability Inventory}

Pediatric Evaluation of Disability Inventory (PEDI) is an instrument for infants and young children aged 6 months to 7.5 years old (Jan, 2002), who are diagnosed with cerebral palsy, autism, or mental retarda- tion. And it measures routine functional activities in three domains: self-care, mobility, and social function by parents and teachers (Jan, 2002). This scale consists of the "child's basic information" and the "scale and score". The former is the basic information of children, which is asked to fill or tick based on the information of the children as detailed as possible and it would be only used as data statistics. It will be kept secretly, and the latter is the specific content of evaluation, including 177 projects consisting of 54 items of self-care, 58 items of mobility, and 65 items of social function. All of which score 0 or 1 . If children cannot be competent or limited in most cases, it scores 0 . On the contrary, if children in most cases are able to competent, it scores 1 . Both of "child's basic information" and "scale and score" are demanded to be realistically evaluated and ticked by parents or teachers.

\subsection{Procedure}

Our study includes pretest and posttest. Before applying the Game System for Rehabilitation based on Kinect, we firstly had a pretest for all children with MR participated in our study through using PEDI to assess the present level of ADL. And then, we formulated a personal rehabilitation plan which met the demand of individual development according to the results of three sub-scales of PEDI for every child. After that, all children would have rehabilitation based on the company and guidance of professional experimenters for a month. Finally, through using PEDI, we organized a posttest for all participated children to assess the level of ADL after the rehabilitation. And we compared the results they obtained in pretest and posttest to assess the effectiveness of Game System for Rehabilitation based on Kinect.

\subsection{Statistical analyses}

Statistical analyses were conducted with IBM SPSS software version 20.0. Repeated-measures ANOVA and $t$ test were used to analyze the effects of Game System for Rehabilitation Based on Kinect.

The scores of the same sub-scale both in pretest and posttest were summed. Two-way (time $\times$ sub-scale) ANOVA were performed to see if there are significant difference between pretest and posttest. Post-hoc paired sample $t$ test was used to determine if there was significant difference in subscale scores between pretest and posttest.

\section{RESULT}

Two evaluation results of PEDI scores were analyzed by repeated-measure ANOVA. The results of posttest are significantly different from the pretest in statistics $(\mathrm{F}=233.256, \mathrm{p}=0.000)$. Furthermore, the two assessment results of three aspects of PEDI (self-care, mo- 
bile ability, and communication ability) were analyzed by paired samples $t$ test. The results showed that, after the training of Game System for Rehabilitation based on Kinect, three aspects all have significant improvements; the results are presented in Table 1:

Table 1. Rresults of paired sample $t$ test

\begin{tabular}{llllll}
\hline & $M$ & $S D$ & $t$ & $d f$ & $p$ \\
\hline Self-care & -6.125 & 4.954 & -13.084 & 111 & 0.000 \\
Mobility & -2.348 & 3.069 & -8.098 & 111 & 0.000 \\
$\begin{array}{l}\text { Social } \\
\text { function }\end{array}$ & -9.893 & 7.895 & -13.261 & 111 & 0.000 \\
\hline
\end{tabular}

\section{CONCLUSIONS \& DISCUSSIONS}

\subsection{Effectiveness}

The purpose of this study was to evaluate the effect of Game System for Rehabilitation based on Kinect, 112 children with mental retardation were selected and they had been trained for a month. The effect was evaluated by the improvement in child's performance

From the statistical analysis of the results, we can see that children with mental retardation have improved self-care, mobility and social function after the application of Game System for Rehabilitation based on Kinect.

Participants showed the greatest progress in social function which is followed by self-care, and the smallest progress in mobility. During games, trainers actively guided the pronunciation of children, which promoted them to communicate with others; in addition, games greatly improved the enthusiasm of children (Miskam, 2014), and it also makes them more willing to communicate with others. So they got the greatest progress in social function (Mohd, 2014). Children with MR often chose upper and lower limbs rehabilitation program. Upper and lower limbs rehabilitation program is mainly related to the gross and fine motor. Through upper and lower limbs rehabilitation games, they have obvious promotion both in the gross and fine motor movement. So they showed the remarkable progress in self-care. Children with MR showed little change in mobility, whose reason may be that they have only light disorder in limb motor and they show good performance before rehabilitation, so the change was not very obvious.

Game System for Rehabilitation based on Kinect adopts the form of game that makes the rehabilitation more exciting. The immersive of Game System for Rehabilitation based on Kinect allows children to be personal on the scene, and they could play games by the use of their body or language rather than simply using keyboard and mouse.

In summary, after the application of Game System for Rehabilitation based on Kinect, children are significantly improved in self-care, mobility, and social function. Obviously, the Game System for Rehabilitation based on Kinect actually is helpful for the reha- bilitation of children with mental retardation.

\subsection{Prospects}

The Game System for Rehabilitation based on Kinect has a broad application prospect.

First, the Game System for Rehabilitation based on Kinect is interesting, and it enhances its attraction, so that children are more willing to accept this kind of rehabilitation (Verstraete, 2006). At the same time, it not only can be applied in mental retardation, but also can be applied in other handicapped as a new method of rehabilitation (Chang Y, 2013 \& 2011).

Second, many different institutions can use the Games, such as special schools, rehabilitation institutions, welfare homes, hospitals, communities and families. Individuals can choose games which are in different degrees of difficulty according to their own ability. Trainers could make reasonable rehabilitation plan and choose appropriate games based on the characteristics of the particular individual.

At last, the cGame System for Rehabilitation based on Kinect can bring a certain therapeutic effect according to our results. During the training, scores and the specific performance of patients can reflect real-time recovery situation, so that trainers could adjust the training to make children insist on rehabilitation for a long time. Meanwhile, it overcomes some shortcomings of traditional rehabilitation, such as boredom, and provides special groups with a new means of rehabilitation.

It is a new way of rehabilitation, and it's believed that the Game System for Rehabilitation based on Kinect will be used more often in the future.

\subsection{Insufficiencies \& improvements}

Although from the statistical analysis of result, we could see that Game System for Rehabilitation based on Kinect is very effective for children with mental retardation, there are still several insufficiencies in this study as follows:

1) 112 children were chosen, and the amount of data is not enough so that the results are lack of reliability in some degree.

2) There are some disturbance when carry on the rehabilitation, which has influenced on the effect of Game System for Rehabilitation based on Kinect more or less.

3) The participants of the study are all mental-retarded children, and it cannot represent the other disorders.

In the further research, these problems can be solved from 3 aspects: At first, the selection of participants should be strict and the amount of participants should be expanded; in addition, the environment of rehabilitation should be controlled to create more suitable environment of rehabilitation; finally, we will study on other disorders as complement. 


\section{ACKNOWLEDGMENT}

This study is one of achievements of the project: An interdisciplinary research of early detection, intervention, education for children with autism (12\&ZD229), which is one of the major projects of National Planning Office of Philosophy and Social Science. The authors would like to thank people in NPOPSS for their contributions.

\section{REFERENCES}

[1] Alankus, G., Lazar, A., May, M. et al. Towards customizable games for stroke rehabilitation. Proceedings of the 28 th international conference on human factors in computing systems, pp: 2113-2122.

[2] Association A P. 2000. DSM-IV-TR: Diagnostic and Statistical Manual of Mental Disorders (4th ed.). American Psychiatric Press Inc.

[3] Axline, V.M. 2012. Play Therapy. Ballantine Books

[4] Bandeira, C., Massetti, T., Dias, T. et al. 2014. Transfer of motor learning from virtual to natural environments in individuals with cerebral palsy. Research in Developmental Disabilities. 35(10): 2430-2437.

[5] Bao, X., Mao, Y., Lin, Q. et al. 2013. Mechanism of Kinect-based virtual reality training for motor functional recovery of upper limbs after subacute stroke. Neural Regeneration Research, 8(31): 2904

[6] Bartoli, L., Corradi, C., Garzotto, F. et al. 2013. Exploring motion-based touchless games for autistic children's learning. Proceedings of the 12th International Conference on Interaction Design and Children. ACM, pp: 102-111.

[7] Bonnechere, B., Jansen, B., Omelina, L. et al. 2014. Can serious games be incorporated with conventional treatment of children with cerebral palsy? A Review. Research in Developmental Disabilities. 35: 1899-1913.

[8] Burkhart, J. E., Fox, R., Rotatori, A. F. 1985. Obesity of mentally retarded individuals: prevalence, characteristics, and intervention. American Journal of Mental Deficiency, 90(3): 303-312.

[9] Chang, Y. 2011. A Kinect-based system for physical rehabilitation: A pilot study for young adults with motor disabilities. Research in Developmental Disabilities, 32(6): 2566-2570.

[10]Chang, Y. 2013. A Kinect-based upper limb rehabilitation system to assist people with cerebral palsy. Research in Developmental Disabilities, 34(11): 3654-3659.

[11]Chung, I.C., Huang, C.Y., Yeh, S.C. et al. 2014. Developing Kinect games integrated with virtual reality on activities of daily living for children with developmental delay. Advanced Technologies, Embedded and Multimedia for Human-centric Computing. Springer Netherlands, pp: 1091-1097.

[12]Daily, D., Ardinger, HH. Holmes, GE. 2000. Identification and evaluation of mental retardation. American Family Physician, 61(4): 1059-1067+1070.
[13]Di Tore, S., D'Elia, F., Aiello, P. et al. 2012. Didactics, movement and technology: New frontiers of the human-machine interaction. Journal of Human Sport and Exercise, 7(1): 178-183.

[14]Duarte, J., Vila C.V., Vila, J. et al. 2013. Advancing the playing field: A look at how virtual reality can change the future of anatomy teaching learning process. The FASEB Journal, 27(1): 960.42.

[15]El-laithy, R.A., Huang, J., Yeh, M. 2012. Study on the use of Microsoft Kinect for robotics applications. Position Location and Navigation Symposium (Plans), 2012 IEEE/ION. IEEE, pp: 1280 - 1288.

[16]Feliciano, L., Steers, ME., Elite-Marcandonatou, A. et al. 2009. Applications of preference assessment procedures in depression and agitation management in elders with dementia. Clinical Gerontologist, 32(3): 119-123.

[17]Fernando, F.A., Susana, J.M., Sanatamaria, J.J. et al. 2012. Video games as a complementary therapy tool in mental disorders: PlayMancer, an European multicentre study. Journal of Mental Health, 21(4): 364-374.

[18] Gualtieri, C.T., Schroeder, S.R., Hicks, R.E. et al. 1986. Tardive dyskinesia in young mentally retarded individuals. Archives of General Psychiatry, 43(4): 335-340.

[19]Hsu, H.M.J. 2011. The potential of Kinect as interactive educational technology. Proc. 2nd Int. Conf. on Education and Management Technology, 1(5): 334-338.

[20]Hsu. J.H. 2011. The potential of Kinect in education. International Journal of Information and Education Technology, 1(5): 365-370.

[21]Jan, W.H. \& Custers. 2002. Pediatric evaluation of disability inventory: the Dutch adaption. Utrecht University.

[22] Jiang, H. \& Jie, X. 2013. Kinect-based rehabilitation training assistant system and implementation. 2013 International Conference on Software Engineering and Computer Science. Atlantis Press, pp: 202-204.

[23]Lange, B., Chang, C.Y., Suma, E. et al. 2011. Development and evaluation of low cost game-based balance rehabilitation tool using the Microsoft Kinect sensor. Engineering in Medicine and Biology Society, EMBC, 2011 Annual International Conference of the IEEE. IEEE, pp: 1831-1834.

[24]Lee K, M. \& James E, M. 1993. Communication intervention for adults with severe mental retardation. Topics in Language Disorders, 13(3): 47-60.

[25]Liebling, D. \& Morris, M.R. 2012. Kinected browser: depth camera interaction for the web. Proceedings of the 2012 ACM International Conference on Interactive Tabletops and Surfaces. ACM, pp: 105-108.

[26]Long, E.S. \& Miltenberger, R.G. 1998. A review of behavioral and pharmacological treatments for habit disorders in individuals with mental retardation. Journal of Behavior Therapy and Experimental Psychiatry, 29: 143-156.

[27]Luck, G., Riikkilä, K., Erkkilä, J. et al. 2006. Exploring relationships between level of mental retardation and features of music therapy improvisations: A computational approach. Nordic Journal of Music Therapy, 15(1): 30-48.

[28]Luna-Oliva, L., Ortiz-Gutiérrez, R.M., Piédrola, R.M. et al. 2013. Kinect Xbox 360 as a therapeutic modality for 
children with cerebral palsy in a school environment: A preliminary study. Neuro Rehabilitation, 33(4): 513-521.

[29]Marie, B. \& Heidi, S. 2011. An intensive virtual reality program improves functional balance and mobility of adolescents with cerebral palsy. Pediatric Physical Therapy, 23(3):258-266

[30] Marnie E, R., Grant T, H., Catherine A, C. 1992. An evaluation of a maximum security therapeutic community for psychopaths and other mentally disordered offenders. Law and Human Behavior, 16(4): 399-412.

[31] Miskam, A.M., Masnin, S.F.N., Jamhuri, M.H. et al. 2014. Encouraging children with autism to improve social and communication skills through the game-based approach. Procedia Computer Science, 42: 93-98.

[32] Miskam, M.A., Masnin, N.F.S., Jamhuri, M.H. et al. 2014. Encouraging children with autism to improve social and communication skills through the game-based approach. Procedia Computer Science, 42: 93-98.

[33] Murphy, C., Boyle, C., Schendel, D. et al. 1998. Epidemiology of mental retardation in children. Mental Retardation and Developmental Disabilities Research Reviews, 4(1): 6-13.

[34]Niklasson, L., Rasmussen, P., Gillberg, C. et al. 2009. Autism, ADHD, mental retardation and behavior problems in 100 individuals with 22q11 deletion syndrome. Research in Developmental Disabilities, 30(4): 763-773.

[35]Parry, I., Carbullido, C., Kawada, J. et al. 2014. Keeping up with video game technology: Objective analysis of Xbox Kinect ${ }^{\mathrm{TM}}$ and PlayStation 3 Move $^{\mathrm{TM}}$ for use in burn rehabilitation. Burns: Journal of the International Society for Burn Injuries, 40(5): 852-859.

[36]Pereira, F., Silva, C., Alves, M. 2011. Virtual fitting room augmented reality techniques for e-commerce. ENTER Prise Information Systems, 27: 62-71.

[37]Petrovska, S. 2013. Role of the game in the development of preschool child. Procedia-Social and Behavioral Sciences, 92: 880-884.

[38] Pompeu, J.E., Arduini, L.A., Botelho, A.R. et al. 2014. Feasibility, safety and outcomes of playing Kinect adventures! For people with Parkinson's disease: a pilot study. Physiotherapy, 100(2): 162-168.

[39]Ritterband-Rosenbaum, A., Christensen, M.S., Nielsen, J.B. 2012. Twenty weeks of computer-training improves sense of agency in children with spastic cerebral palsy. Research in Developmental Disabilities, 33(4): 1227-1234.

[40]Roebel, A.M. \& MacLean Jr, W.E. 2007. Spontaneous eye-blinking and stereotyped behavior in older persons with mental retardation. Research in Developmental Disabilities, 28(1): 37-42.

[41] Scardovelli, T.A. \& Frere, A.F. 2014. The design and evaluation of a peripheral device for use with a computer game intended for children with motor disabilities[EB/OL].

[2014.10.12] http://www.sciencedirect.com/science/article/pii/S01692 60714003472.

[42] Shea, E.S. 2006. Mental retardation in children ages 6 to 16. Seminars in Pediatric Neurology, (13): 262-270.

[43]Tudor, I. \& Tudor, M. 2013. Leisure sports activities impact on adults personal development and quality of life. Procedia-Social and Behavioral Sciences, 84(9): 1090-1094.

[44] Verstraete, S.J.M. 2006. Increasing children's physical activity levels during recess periods in elementary schools: the effects of providing game equipment. The European Journal of Public Health, 16(4): 415-419.

[45] Yeung, L.F., Cheng, K.C., Fong, C.H. et al. 2014. Evaluation of the Microsoft Kinect as a clinical assessment tool of body sway. Gait \& Posture, 40(4): 532-538.

[46]Zhang, Y. 2006. Population characteristics and the existence and development of the MR -- a survey of 216 people with MR in Nanjing. Population and Society, 22(1): 41-45.

[47]Zhang, Z. 2012. Microsoft Kinect sensor and its effect. Multi Media, IEEE, 19(2): 4-10. 